\title{
Pengukuran Indeks Keamanan Proses Produksi MMA (Methyl Methacrylate) dengan ISV (Index Safety Value)
}

\author{
Dyan Hatining Ayu Sudarni ${ }^{1 *}$, Juwari ${ }^{2}$ \\ ${ }^{1)}$ Teknik Kimia, Teknik, Universitas PGRI Madiun \\ ${ }^{2)}$ Teknik Kimia, Teknik Industri, Institut Teknologi Sepuluh Nopember \\ *email: dhy.anayu@gmail.com
}

Received: 12/06/2018; Revised: 24/06/2018; Accepted: 24/06/2018

\begin{abstract}
Abstrak
Industri kimia memiliki berbagai tahapan proses dalam setiap produksi. Setiap tahapan prosesnya memiliki tingkat kegagalan atau risiko dilihat dari bahan kimia, kondisi proses dan peralatan. Metode penilaian kegagalan penelitian sebelumnya mengintegrasikan tiga aspek yang dibagi menjadi dua parameter utama. Penelitian ini berkaitan dengan penilaian keamanan dengan tiga integrasi yang disebut nilai keamanan indeks (ISV). Cara penilaian dengan ISV dimulai dengan menentukan parameter, penilaian tiap parameter dan selanjutnya diintegrasikan. Penelitian ini mengambil produksi methyl methacrylate (MMA) dengan acetone cyanohydrin ( $\mathrm{ACH}$ ) sebagai kasus yang akan dipelajari. Parameter utama berupa bahan kimia dan kondisi operasi. Produksi MMA memiliki empat langkah proses produksi. Dimulai dengan produksi HCN, ACH, HMPA / HMPSE dan yang terakhir MMA. Dari empat langkah tersebut HCN memiliki tingkat risiko yang tinggi, dengan nilai indeks 0,299 dan karakteristik'Moderate'. Sedangkan risiko yang rendah adalah MMA dengan nilai indeks 0,201 dan karakteristik 'Light'
\end{abstract}

Kata kunci: Methyl Methacrylate, Tingkat risiko, Penilaian keamanan, Index Safety Value, Standarisasi

\begin{abstract}
The chemical industry has various stages of production processes. The level of the risk of fail can be discerned from chemicals, the process condition and equipment. The method of risk assessment failure to research has not previously been integrating the three aspects which is divided into two main of the parameters. This research deals with an assessment of the safety of with three aspect integration called index safety value (ISV). The assessment technique ISV was with a determining parameters, assessment of each ISV parameter, and assessment with integration. The research use production methyl methacrylate (MMA) with acetone cyanohydrin (ACH) as the case to be studied. Main parameters are safety chemicals and safety conditions in an operation. Production of MMA has four steps production process. The first step is HCN product, ACH product, HMPA/HMPSE and the last is the production of MMA. From the four steps the HCN product has higher risk level, with an index value of 0,299 and moderate characteristics. The low less risk level is step of production of MMA with index value 0,201 and light characteristics
\end{abstract}

Keywords: Methyl Methacrylate, Risk Level, Safety Assessment, Index Safety Value, Standardization

\section{PENDAHULUAN}

Keamanan merupakan suatu strategi yang digunakan untuk mengurangi risiko dari kecelakaan. Salah satu metode yang terkenal sampai sekarang adalah DOW Fire. Metode ini betujuan untuk mengukur kerusakan yang disebabkan oleh potensial terjadinya kebakaran dan insiden ledakan (Dow Chemical Company, 1987).
Pengukuran atau penilaian setiap metode bertujuan untuk mengurangi risiko kegagalan seuatu proses. Pengurangan risiko kecelakaan pada tiap proses dapat diaplikasikan dengan strategi keselamatan yang inheren (Inherent) untuk mengurangi bahaya (Heikkila, 1999). Inherent safety adalah konsep, pendekatan keamanan yang berfokus pada menghilangkan atau 
mengurangi bahaya yang berhubungan dengan serangkaian kondisi. Proses identifikasi dan penerapan keselamatan inheren dalam kontek tertentu disebut inherent safety design. Sebuah tahapan proses pengurangan bahaya diklasifikasikan menjadi empat kategori proses kontrol, yaitu inheren, pasif, aktif dan prosedural. Proses kontrol dengan inheren ini lebih lengkap dibandingkan dengan kategori proses kontrol pasif, aktif dan prosedural (Kletz, 2009).

Sebuah pabrik yang dibuat lebih aman dengan menambahkan peralatan kontrol dapat mengurangi kegagalan sehingga dapat dikatakan sebagai peralatan keamanan yang mendasar. Selain peralatan yang dikontrol, banyak strategi telah diperkenalkan untuk mengurangi atau meminimalkan konsekuensi kecelakaan. Dengan demikian harus dibangun suatu keadaan yang aman agar pekerja dapat mengurangi tingkat kecelakaan serta harus ada pemeliharaan peralatan untuk mencegah terjadinya kegagalan peralatan (Kletz, 2009).

Pada umumnya untuk perhitungan keamanan suatu proses terbagi satu atau dua parameter saja. Salah satu contoh metode perhitungan kegagalan dengan NuDITS terbagi atas dua parameter (Ahmad et al, 2014). Sebenarnya pembagian parameter suatu keamanan dapat di bagi menjadi berbagai macam.

Salah satu pembagian parameter adalah penilaian keamanan bahan kimia, dimana penilaian keamanan bahan kimia dibagi menjadi : tingkat mudah terbakar, meledak, bahan yang mengandung racun dan bahan kimia mudah bereaksi. Sedangkan untuk keamanan proses produksi terbagi menjadi : temperatur, tekanan dan proses inventori (inventaris).
Penelitian ini membahas tentang penilaian keamanan dengan integrasi yang menggunakan tiga aspek (bahan kimia, kondisi proses dan peralatan). Penelitian ini mengambil kasus produksi methyl methacrylate (MMA) dengan bahan baku acetone cyanohydrin (ACH) (Edwards, 1993). Berdasarkan perhitungan Edwards tahun 1993 masih banyak kekurangan dalam menentukan setiap parameter. Maka dari itu dilakukan penelitian dengan fokus utama pengembangkan penilaian keamanan yang baru dengan integrasi. Cara penilaian keamanan ini dengan cara menggunakan parameter kemanan bahan kimia dan keamanan kondisi prosesnya.

\section{METODE PENELITIAN}

Menghitung tingkat keamanan dengan ISV yaitu menggunakan dua parameter utama. Parameter yang digunakan dalam penelitian ini adalah keamanan proses dan keamanan kimia berdasarkan penilaian setiap peralatan.. Tahapan perhitungan metode baru ini;

\section{a. Penentuan Parameter}

Parameter utama yang digunakan untuk penilaian ini adalah kondisi keamanan saat proses dan keamanan bahan kimianya. Parameter dihitung berdasarkan setiap alat yang dilewati saat proses pembuatan MMA berdasarkan PFD (Chauvel dan Lefebvre, 1998). Parameter peralatan yang mempunyai kontribusi terjadinya ketidak amanan adalah reaktor, alat penukar panas, kolom. Perhitungan untuk memperoleh Index Safety Value (ISV)

$$
\mathrm{ISV}=\mathrm{IVC}+\mathrm{IVP}
$$

Index Safety Value (ISV) adalah total dari keleluruhan nilai ketidak amanan, Inherent Value Chemical (IVC) adalah parameter keamanan berdasarkan jenis 
bahan kimia yang nilainya dapat diketahui dari MSDS. Sedangkan Inherent Value Process (IVP) adalah keamanan dilihat dari saat kondisi operasi suatu pabrik yang akan diteliti.

\section{b. Perhitungan dengan Metode Index Safety Value}

Parameter dibagi menjadi dua parameter utama yang terdiri dari IVC dan IVP. Setiap parameter mempunyai sub parameter-parameter dengan rumusan sebagai sebagai berikut,

$$
\begin{aligned}
& \mathrm{IVC}=\mathrm{V}_{\mathrm{FL}}+\mathrm{V}_{\mathrm{EXP}}+\mathrm{V}_{\mathrm{TOX}}+\mathrm{V}_{\mathrm{REAC}} \\
& \mathrm{IVP}=\mathrm{V}_{\mathrm{T}}+\mathrm{V}_{\mathrm{P}}+\mathrm{V}_{\mathrm{HR}}+\mathrm{V}_{\mathrm{I}}
\end{aligned}
$$

\section{c. Penilaian dengan Integrasi}

Penilaian Integrasi adalah penilaian secara total dengan persamaan (1) yang menggabungkan dengan semua aspek parameter.

\section{d. Analisa Tingkat Keamanan Tiap Langkah dengan Standarisasi}

Analisa tingkat keamanan untuk mengetahui bahaya pada suatu proses produksi menggunakan karakteristik penilaian pada Tabel 1. Setiap proses produksi suatu pabrik terdapat beberapa langkah produksi. Langkah-langkah dalam proses produksi tersebut diantaranya persiapan, reaksi, pemisahan dan pemurnian. Tabel 1 untuk mempermudah menentukan tingkat potensi terjadinya suatu kegagalan (Sudarni dan Juwari, 2016).

Tabel 1. Karakteristik Penilaian Tingkat Bahaya

\begin{tabular}{cc}
\hline Tingkat Bahaya & Indek \\
\hline Severe & $0,751-1$ \\
Heavy & $0,501-0,75$ \\
Moderate & $0,251-0,5$ \\
Light & $0 \quad-0,25$ \\
\hline Nilai dari tabel tersebut & jika \\
mendekati satu (x mendekati & $1)$ maka
\end{tabular}

parameter sangat berkaitan yang menyebabkan insiden. Sedangkan jika nilai korelasi mendekati nol (x mendekati 0) maka parameter tersebut tidak terlalu berkaitan. Untuk itu dapat diperkirakan area atau langkah mana yang akan diprioritaskan terlebih dahulu agar dapat mengurangi ketidak amanan. Jadi setiap proses produksi dalam satu pabrik dapat dikatakan mempunyai rentangan indek (Sudarni dan Juwari, 2016).

\section{HASIL DAN PEMBAHASAN}

Penelitian ini terfokus pada langkah pembuatan methyl methacrylate (MMA) dengan menggunakan acetone cyanohydrin $(\mathrm{ACH})$. Proses produksi MMA dengan ACH terbagi menjadi empat langkah yaitu: a. Reaksi dengan senyawa Ammonia, Metana dan oksigen

b. HCN dan Aceton

c. ACH dan Sulfuric Acid

d. HMPA/HMPASE dan Metanol

Penilaian dengan ISV ini terbagi menjadi dua parameter utama. Inherent Value Chemical (IVC) dan Inherent Value Process (IVP). Penilaian ini dilakukan perhitungan sesuai dengan persamaan 2 dan 3 pada Tabel 2. Tabel 2 dan 3 merupakan penjumlahan sesuai dengan tabel penentuan parameter setiap langkah proses produksi. Tabel 2 menjelaskan Inherent Value Chemical sedangkan Tabel 3 menjelaskan Inherent Value Process.

Tabel 2. Perhitungan Inherent Value Chemical dengan Metode ISV

\begin{tabular}{lcccc}
\hline \multicolumn{1}{c}{ Produk } & $\mathbf{V}_{\text {FL }}$ & $\mathbf{V}_{\text {EXP }}$ & $\mathbf{V}_{\text {TOX }}$ & $\mathbf{V}_{\text {REAC }}$ \\
\hline HCN & 116,6 & 153,8 & 145 & 4 \\
ACH & $-145,3$ & 64,2 & 780 & 6 \\
HMPA/HMPSE & $-44,9$ & 145,9 & 620 & 4 \\
MMA & 32,2 & 51,3 & 400 & 4 \\
\hline
\end{tabular}


Tabel 3 Perhitungan Inherent Value Process dengan Tabel 7. Hasil Karakteristik Penilaian Tingkat Metode ISV

\begin{tabular}{lllll}
\hline \multicolumn{1}{c}{ Produk } & \multicolumn{1}{c}{$\mathbf{V}_{\mathbf{T}}$} & \multicolumn{1}{c}{$\mathbf{V}_{\mathbf{P}}$} & \multicolumn{1}{c}{$\mathbf{V}_{\mathbf{H R}}$} & \multicolumn{1}{c}{$\mathbf{V}_{\mathbf{I}}$} \\
\hline HCN & 1200 & 3,4 & -3757 & 64 \\
ACH & 38 & 1 & -458 & 91 \\
HMPA/HMPSE & 150 & 7 & Small & 98 \\
MMA & 130 & 7 & Small & 198 \\
\hline
\end{tabular}

Selanjutnya dilakukan integrasi dengan tied. Cara menggunakan tied data statistik ini merupakan pemberian skor berdasarkan urutan mulai dari yang terendah diberikan skor terkecil dan seterusnya. Hasil nilai terlihat seperti pada Tabel 4 dan 5 .

Tabel 4. Integrasi Inherent Value Chemical dengan Tied Data Statistik

\begin{tabular}{lcccc}
\hline \multicolumn{1}{c}{ Produk } & $\mathbf{V}_{\text {FL }}$ & $\mathbf{V}_{\text {EXP }}$ & $\mathbf{V}_{\text {TOX }}$ & $\mathbf{V}_{\text {REAC }}$ \\
\hline HCN & 4 & 4 & 1 & 2 \\
ACH & 1 & 2 & 4 & 4 \\
HMPA/ & 2 & 3 & 3 & 2 \\
HMPSE & 3 & 1 & 2 & 2 \\
MMA & 3 & \\
\hline
\end{tabular}

Tabel 5. Integrasi Inherent Value Process dengan Tied Data Statistik

\begin{tabular}{lcccc}
\hline \multicolumn{1}{c}{ Produk } & $\mathbf{V}_{\mathbf{T}}$ & $\mathbf{V}_{\mathbf{P}}$ & $\mathbf{V}_{\mathbf{H R}}$ & $\mathbf{V}_{\mathbf{I}}$ \\
\hline HCN & 4 & 3 & 4 & 1 \\
ACH & 1 & 4 & 3 & 2 \\
HMPA/ & 3 & 1,5 & 1.5 & 3 \\
HMPSE & 2 & 1,5 & 1.5 & 4 \\
MMA & 2 &
\end{tabular}

Tabel 6 merupakan perhitungan total dengan metode ISV. Sedangkan table 7 merupakan penilaian karakteristik tingkat bahaya yang akan terjadi sesuai dengan tabel 1.

Tabel 6. Perhitungan Total Metode ISV

\begin{tabular}{lccc}
\hline Produk & IVC & IVP & ISV \\
\hline HCN & 11 & 12 & 23 \\
ACH & 11 & 10 & 21 \\
HMPA/HMPSE & 10 & 7,5 & 17,5 \\
MMA & 8 & 7,5 & 15,5 \\
\hline
\end{tabular}
Bahaya

\begin{tabular}{lcc}
\hline Produk & Indek & Karakteristik \\
\hline HCN & 0.2987 & Moderate \\
ACH & 0.2727 & Moderate \\
HMPA/ & 0.2273 & Light \\
HMPSE & 0.2013 & Light \\
MMA & & \\
\hline
\end{tabular}

Hasil perhitungan keamanan tingkat bahaya yang paling besar adalah saat proses pembuatan MMA dengan $\mathrm{ACH}$ di langkah saat produksi HCN. Hal ini karena reaksi terjadi dengan temperatur tinggi dan mengalami reaksi eksotermis yang tinggi. Berdasarkan karakteristik penilaian tingkat bahaya yang paling cepat mengakibatkan potensi adanya kegagalan atau bahaya terdapat pada langkah pertama dengan karakteristiknya 'Moderate' dan memiliki nilai indek 0,299. Paling kurang berbahaya adalah langkah keempat dengan karakteristik 'Light' yang memiliki nilai indek 0,201. Metode ISV ini hanya dapat dipakai untuk satu proses produksi saja.

\section{KESIMPULAN}

Metode ISV lebih mudah penerapannya dengan membagi parameter Inherent Value Chemical dan Inherent Value Process. Hasil dari perhitungan ISV dapat disimpulkan bahwa tingkat bahaya yang paling besar saat proses pembuatan MMA adalah langkah saat produksi $\mathrm{HCN}$ dengan nilai indek 0,299 (Moderate). Sedangkan yang paling kurang berbahaya adalah langkah keempat yaitu pada saat produksi MMA dengan nilai indek 0,201 (Light). 


\section{DAFTAR RUJUKAN}

Ahmad, S. I., Hashim, H., Hassim, M.H. (2014). Numerical Descriptive Inherent Safety Technique (NuDIST) for Inherent Safety Assessment Petrochemical Process. J. Process Safety and Environmental Protection, 92, 379-389.

Chauvel, A., \& Lefebvre, G. (1998) Petrochemical Processes: Technical and Economic Characteristics Second Edition. Paris: Gulf Publishing Company

Dow Chemical Company. (1987). Dow's Fire \& Explosion Index Hazard Classification Guide, sixth ed. New York: American Institute of Chemical Engineers
Edwards, D.W., \& Lawrence, D. (1993). Assessing the inherent safety of chemical process routes: is there a relation between plant costs and inherent safety. Trans. IChemE., 71 (B), 252-258.

Heikkila, A. M. (1999). Inherent Safety Process Plant Design - an Index Based Approach. Helsinki: University of Technology.

Kletz, T. (2009). Inherently Safer Chemical Processes, second edition. New York: John Wiley \& Sons, Inc.

Sudarni, D. H. A., \& Juwari, H. R. (2016). Process Safety Index in Chemical Process, The $2^{\text {nd }}$ International Seminar on Science and Technology-ITS. Vol 183-184. 